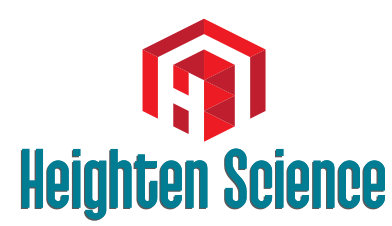

P U B L I C I T I O N S Corporation

\title{
Impact of four obesity interventions on biometric measures of individuals positive and negative for food addiction
}

\author{
Trina Aguirre $^{1 *}$, Leeza Struwe ${ }^{2}$, Ann Koehler ${ }^{1}$, Rebecca \\ Kreman ${ }^{3}$, Rebecca Bowman ${ }^{3}$, Erica Schulte ${ }^{4}$, Kayla Pierce ${ }^{1}$, \\ Molly Bloodgood ${ }^{1}$ and Jeffrey Holloway ${ }^{3}$
}

'University of Nebraska Medical Center, College of Nursing, West Nebraska Division, 1601 East 27th St., Scottsbluff, NE, USA 69361-1815, USA

2University of Nebraska Medical Center, College of Nursing, Niedfelt Nursing Research Center, PO Box 880220, Lincoln, NE 68588-0220, USA

${ }^{3}$ Regional West Physicians Clinic, Medical Plaza North, Two West 42nd Street, Scottsbluff, NE 69361, USA

4University of Michigan, Department of Psychology, 2257 East Hall, 530 Church Street, Ann Arbor, MI 48109, USA

\begin{abstract}
*Address for Correspondence: Trina Aguirre, University of Nebraska Medical Center, College of Nursing, West Nebraska Division, 1601 East 27th St., Scottsbluff, NE 69361-1815, USA, Tel: (308) 632-0429; Email: taguirre@unmc.edu

Submitted: 21 September 2018

Approved: 27 September 2018

Published: 28 September 2018

Copyright: ๑ 2018 Aguirre T, et al. This is an open access article distributed under the Creative Commons Attribution License, which permits unrestricted use, distribution, and reproduction in any medium, provided the original work is properly cited
\end{abstract}

Check for updates

\section{Abstract}

Obesity is a major contributor to ill health and numerous comorbidities globally. Recent studies suggest that addictive-like tendencies toward foods, especially highly processed foods, contribute to this epidemic. Therefore, interventions used to treat substance-use disorders may be effective for treating overweight/obese patients with food addiction (based on the Yale Food Addiction Scale, version 2.0). This pilot study evaluated four interventions, selected because of their effectiveness in the treatment of substance-use disorders [motivational interviewing, pharmacotherapy (naltrexonebupropion), pharmacotherapy with motivational interviewing, information control (diet and physical activity instruction)], in overweight/obese individuals with and without food addiction. The food addiction construct identified a distinctive subset of overweight/obese individuals. Through one month, response to interventions differed between food addiction phenotypes with those who were positive for food addiction showing similar or less response to the interventions than those who were negative for the trait. This suggests that individuals with addictive-like tendencies toward food may require longer and more intensive intervention to achieve their goals. The greatest changes in biometric measures occurred between baseline and 1 month during which time participants were attending weekly intervention sessions. Across all groups, those who attended more sessions (dose) was correlated with a reduction in body mass index.

\section{Introduction}

Obesity is a major health issue globally and is associated with increased risk of comorbidities and increased medical expenditures, contributing to the death of at least 2.8 million people each year. Once only prevalent in high income countries, overweight/ obesity is now prevalent in low and middle income countries [1]. Numerous approaches have been tried to address obesity with limited long-term success. Recently it has been suggested that addictive-like tendencies toward foods, especially highly processed foods that are high in fat and sugar, contribute to the epidemic [2-5]. The Yale Food Addiction Scale (YFAS) is a relatively new, validated instrument that is used to assess individuals for food addiction (FA) [6,7]. Recent studies report FA prevalence of 20$25 \%$ in overweight/obese populations [5,8], whereas prevalence was $37.1 \%$ in this study [9]. No known obesity interventions specifically target individuals who are 
positive for FA. If an addictive-like process contributes to obesity for some individuals, then interventions used to treat substance-use disorders may be effective for treating FA $[10,11]$. Therefore, we evaluated four interventions, selected because of their effectiveness in the treatment of substance-use disorders [motivational interviewing (MI), pharmacotherapy (P; naltrexone-bupropion), MI with pharmacotherapy (P+MI), information control (IC; diet and physical activity instruction)], in overweight/obese individuals with and without FA (FA+ and FA-, respectively) with the goal of developing effective interventions for each group.

\section{Methods}

This study was conducted in accordance with IRB protocol 763-16-FB (University of Nebraska Medical Center). Participants received a $\$ 20$ incentive following each session as compensation for their time.

\section{Participants}

Participants were recruited from overweight/obese patients referred to the Healthy Behaviors Clinic by doctors at the Regional West Physicians Clinic in Scottsbluff, Nebraska, USA and through snowballing. Potential participants completed a set of questionnaires as part of the standard Healthy Behaviors Clinic admission process, including the Yale Food Addiction Scale (YFAS 2.0) [12] and a medical history. These instruments were reviewed by a Doctor of Nursing Practice (DNP) who is board certified in Adult Health and Psychiatry to pre-screen potential participants for eligibility. The DNP was also the study prescriber, along with two bariatric surgeons when she was not available.

Eligible individuals were overweight/obese adults age 19-65 years of either sex and any race/ethnicity who could understand/read English. Because treatments were randomly assigned, they also had to meet criteria specific to the pharmacotherapy interventions $(\mathrm{P}, \mathrm{P}+\mathrm{MI})$ (e.g. restrictions on medications, medical conditions, pregnancy/lactation). Nurse researchers informed those who were eligible about the study and consented those choosing to participate.

One hundred five individuals were screened, 83 were enrolled, 14 withdrew, and 8 were ineligible [9]. Seventy-four participants were women and 9 were men [9]. Fiftynine were Caucasian, 23 were Hispanic, and 1 was African-American [9]. Average age was 42.7 [9].

\section{Assessment of food addiction/treatment assignment}

The YFAS 2.0 [12], which adapts the eleven DSM-5 diagnostic indicators of substance-use disorders to the consumption of highly processed foods, was used to assess participants' obesity phenotype (FA+ or FA-). Participants with $\geq 2$ symptoms plus impairment/distress were considered FA+. Those with 0-1 symptoms and/or no impairment/distress were considered FA-. Participants within each phenotype were randomly assigned to one of the treatment groups (IC, MI, P+MI, P).

\section{Interventions}

Interventions were delivered following collection of outcome measures at baseline, $1,2,3$, and 4 weeks and 2, 3, 4, 5, and 6 months.

\section{Intervention Conditions (MI, P+MI)}

MI is an evidence-based, client-centered approach for behavioral change that was developed and is still used for the treatment of addictions [13,14]. MI is theorized to decrease an individual's ambivalence and increase his/her perceived behavioral control by emphasizing personal choice and control in decision-making and by 
affirming the individual's self-management ability [15,16]. Our MI intervention (MI, $\mathrm{P}+\mathrm{MI}$ ) was designed to effect behavior change by sharing information on the benefits of limiting intake of highly processed foods/increasing intake of minimally processed foods (addressing attitudes/beliefs) and providing support to increase perceived behavioral control by decreasing participants' ambivalence and barriers (addressing self-efficacy), thereby supporting participants in limiting their highly processed food intake/increasing their minimally processed food intake. A written MI algorithm was used to ensure fidelity.

\section{Pharmacotherapy Interventions (P, P+MI)}

We selected sustained release naltrexone-bupropion $\left(\right.$ Contrave ${ }^{\circledR}$ ) for our pharmacotherapy interventions (P, $\mathrm{P}+\mathrm{MI})$ because these drugs have been used to treat addictions $[17,18]$. Naltrexone-bupropion produces weight loss by reducing appetite/ cravings and is more effective in promoting weight loss in combination than either drug alone [19]. The naltrexone-buproprion (administered orally) was titrated to the therapeutic dose over the first 4 weeks. Use was discontinued if an individual did not show $\geq 5 \%$ weight loss by the beginning of month 4 .

\section{IC Control Condition}

The IC control group received diet and physical activity information encouraging them to adopt healthier eating (limiting intake of highly processed foods/increasing intake of minimally processed foods) and physical activity behaviors [20]. The other intervention groups received the same information during their baseline visit.

\section{Biometric outcome measures}

We used a Tanita SC-240 bioelectrical impedance analyzer to estimate weight, BMI, percent body fat $(\% \mathrm{BF})$, percent body water (\%BW), basal metabolic rate (BMR), and visceral fat rating (VFR). Percent $B F$ is more closely associated with health outcomes than BMI [21] and tends to be inversely related to \%BW. BMI was included because it is a standard used by WHO and CDC, despite its limitations (accounting only for height/weight, disregarding body symmetries, muscular vs greater fat composition, and genetic differences in body proportions) [21,22]. BMR is an indicator of metabolic efficiency and VFR is an indicator of risk for cardiovascular disease.

\section{Data analysis}

Descriptive statistics $(M, S D)$ were used to characterize variables. Changes in variables over time was determined by subtracting the value at one month from the value at baseline. If the difference was positive, the variable decreased. If negative, the variable increased. Levene's test was used to evaluate equality of variances, independent t-tests were used to evaluate differences among variables, and Pearson's correlations were used to explore relationships among variables. Pairwise deletion was used when there was missing data (missed sessions). Because this was a pilot study, analyses were considered significant at $\alpha=0.10$. Analyses were performed using IBM ${ }^{\circledR}$ SPSS $^{\circledR}$ Statistics (Version 25) software.

\section{Results}

Although interventions were conducted over six months, analyses revealed that the greatest changes were observed at the end of weekly sessions ( 1 month). Therefore, we calculated changes in BMI, \%BF, \%BW, BMR, and VFR between baseline and one month and compared the changes among FA phenotypes. For those in the $\mathrm{P}$ and $\mathrm{P}+\mathrm{MI}$ intervention groups, there were no significant differences $(p>0.10)$ between FA+ and FA- participants for any variable. At 1 month those in the pharmaceutical interventions $(\mathrm{P}, \mathrm{P}+\mathrm{MI})$ would just be achieving the therapeutic dose which may not fully reflect 
the impact of the interventions after longer use. For those in the MI treatment group, change in \%BF ( $p=.073), \% \mathrm{BW}(p=.063)$, BMR ( $p=.058)$, and VFR ( $p=.064)$, differed between FA+ and FA- participants. Percent BF declined almost a percentage point in those who were FA-, but increased slightly in those who were FA+ (Table 1). Percent BW increased over half a percentage point in those who were FA-, but decreased slightly in those who were FA+ (Table 1). BMR declined in both groups, particularly the FA+ group, indicating improved efficiency, however, there was little or no change in VFR (Table 1). Among IC participants, only change in \%BW differed between FA phenotypes ( $p=.068$ ), slightly decreasing in those who were FA- and slightly increasing in those who were FA+.

The greatest improvement in biometric measures was observed for \%BF (decline) and \%BW (increase) among FA- participants in the MI and P intervention groups (Table 1). Changes in BMI and VFR (a calculated variable) were generally small for all FA phenotype-intervention combinations (Table 1). BMR declined for all FA phenotypeintervention combinations except FA+ participants in the IC group (Table 1).

Among all participants, session attendance was positively correlated with change in BMI $(r=.291, p=.034)$ and VFR $(r=.261, p=.065)$ and age was positively correlated with session attendance $(r=.181, p=.097)$. Among treatment groups, session attendance was positively correlated with change in BMI in the P+MI group $(r=.514$, $p=.035$ ); no other correlations were significant. Among FA- participants, age was positively correlated with session attendance for those in the P+MI group $(r=.640$, $p=.0 .34)$. There were no significant correlations among FA+ participants $(p>0.10)$.

\section{Discussion}

Though currently not a clinically recognized diagnosis, the FA construct identified a distinctive subset of overweight/obese individuals. Through one month of weekly sessions, response to interventions differed between FA phenotypes, with those who were FA+ showing similar or less response to the interventions than those who were FA-. This suggests that individuals with addictive-like tendencies toward food may require longer and more intensive intervention to achieve their weight/fat loss goals.

\section{Acknowledgements}

This work was supported by a Research \& Engagement Competitive Award by the Rural Futures Institute at the University of Nebraska. We thank Dr. Jeffrey Holloway, Dr. Jason LaTowsky, and Martha Stricker of Regional West Physician Clinic and Don Graham, consulting pharmacist, for their contributions to this study.

Table 1: Mean ( \pm SD) change in biometric variables over one month by food addiction phenotype (+ or -) and obesity intervention (information control, motivational interviewing, pharmacotherapy, pharmacotherapy with motivational interviewing).

\begin{tabular}{|c|c|c|c|c|c|}
\hline \multirow{2}{*}{ Variable } & \multirow{2}{*}{ FA Phenotype } & \multicolumn{5}{|c|}{ Intervention } \\
\cline { 2 - 6 } & & IC & MI & P & P+MI \\
\hline \multirow{2}{*}{ BMI } & - & $0.53(0.56)$ & $0.61(0.47)$ & $0.89(0.84)$ & $0.32(0.75)$ \\
\cline { 2 - 6 } & + & $0.34(0.65)$ & $0.86(0.80)$ & $0.84(0.58)$ & $0.68(0.91)$ \\
\hline \multirow{2}{*}{ \%BF } & - & $0.11(0.93)$ & $0.98(1.30)$ & $1.32(5.17)$ & $-1.26(2.63)$ \\
\hline \multirow{2}{*}{ \%BW } & + & $0.63(1.03)$ & $-0.34(1.41)$ & $0.11(1.07)$ & $-0.06(2.51)$ \\
\hline \multirow{2}{*}{ BMR } & - & $0.13(0.44)$ & $-0.61(0.86)$ & $-1.38(3.49)$ & $0.82(1.76)$ \\
\hline \multirow{2}{*}{ VFR } & + & $-0.44(0.72)$ & $0.34(1.03)$ & $-0.01(0.79)$ & $0.06(1.59)$ \\
\hline & - & $14.70(42.78)$ & $8.89(21.27)$ & $16.20(175.93)$ & $40.22(56.03)$ \\
\hline & - & $-3.43(53.47)$ & $57.29(54.00)$ & $29.25(41.09)$ & $64.75(159.56)$ \\
\hline
\end{tabular}

SD: Standard Deviation, FA: Food Addiction, IC: Information Control, MI: Motivational Interviewing, P: Pharmacotherapy, P+Ml: Pharmacotherapy with Motivational Interviewing, BMI: Body Mass Index, \%BF: percent Body Fat, \%BW: percent Body Water, BMR: Basal Metabolic Rate, VFR: Visceral Fat Rating. Changes in variables over time was determined by subtracting the value at one month from the value at baseline (positive differences indicate that the variable decreased, negative differences indicate that the variable increased). For each FA phenotype-intervention combination, $n$ ranged from 7 to 10 . 


\section{References}

1. WHO, 2017; Obesity fact files. Ref.: https://goo.gl/BqP4B9

2. Schulte EM, Avena NM, Gearhardt AN. Which foods may be addictive? The roles of processing, fat content, and glycemic load. PLoS One. 2015; 18; 10: e0117959. Ref.: https://goo.gl/7kze2Q

3. Flint $A J$, Gearhardt AN, Corbin WR, Brownell KD, Field AE, et al. Food-addiction scale measurement in 2 cohorts of middle-aged and older women. Am J Clin Nutr. 2014; 99: 578-586. Ref.: https://goo.gl/QjQjCh

4. Iozzo P, Guiducci L, Guzzardi MA, Pagotto U. Brain PET imaging in obesity and food addiction: current evidence and hypothesis. Obes Facts. 2012; 5: 155-164. Ref.: https://goo.gl/Xd7sjQ

5. Pursey KM, Stanwell P, Gearhardt AN, Collins CE, Burrows TL. The prevalence of food addiction as assessed by the Yale Food Addiction Scale: a systematic review. Nutrients. 2014; 6: 4552-4590. Ref.: https://goo.gl/HVUP9u

6. Gearhardt AN, Corbin WR, Brownell KD. Preliminary validation of the Yale food addiction scale. Appetite. 2009; 52: 430-436. Ref.: https://goo.gl/TN9UCR

7. Gearhardt AN, Roberto CA, Seamans MJ, Corbin WR, Brownell KD. Preliminary validation of the Yale Food Addiction Scale for children. Eat Behav. 2013; 14: 508-512. Ref.: https://goo.gl/tyAffZ

8. Imperatori $\mathrm{C}$, Innamorati $\mathrm{M}$, Contardi $\mathrm{A}$, Continisio $\mathrm{M}$, Tamburello $\mathrm{S}$, et al. The association among food addiction, binge eating severity and psychopathology in obese and overweight patients attending low-energy-diet therapy. Comprehensive psychiatry. 2014; 55: 1358-1362. Ref.: https://goo.gl/CiqrSb

9. Aguirre T, Bowman RB, Kreman R, Holloway J, LaTowsky J, et al. Pre-intervention characteristics in weight loss participants scoring positive and negative for food addiction. 2018. Oatext.com. Ref.: https://goo.gl/fcvgRx

10. Lennerz B, Lennerz JK. Food Addiction, High-Glycemic-Index Carbohydrates, and Obesity. Clin Chem. 2018; 64: 64-71. Ref.: https://goo.gl/VKu5Vz

11. Steward T, Mestre-Bach G, Vintró-Alcaraz C, Lozano-Madrid M, Agüera Z, et al. Food addiction and impaired executive functions in women with obesity. European Eating Disorders Review. 2018; Ref.: https://goo.gl/sk8CDV

12. Gearhardt AN, Corbin WR, Brownell KD. Development of the Yale Food Addiction Scale Version 2.0. Psychology of Addictive Behaviors. 2016; 30: 113-121. Ref.: https://goo.gl/97KDiU

13. Miller WR. Motivational interviewing with problem drinkers. Behavioural and Cognitive Psychotherapy. 1983; 11: 147-172. Ref.: https://goo.gl/NPQvZZ

14. Tober G. Motivational Interviewing and Behaviour Change in Addiction Treatment. Textbook of Addiction Treatment: International Perspectives. 2015; 779-7791. Ref.: https://goo.gl/y5Spsp

15. Aguirre T, Koehler A, Wilhelm S. Bio-Impedance Analysis Measures in a Rural Latina Community. Journal of Public Health. 2014; 3:1-3. Ref.: https://goo.gl/vvhDA7

16. Emmons KM, Rollnick S. Motivational interviewing in health care settings: opportunities and limitations. American journal of preventive medicine. 2001; 20: 68-74. Ref.: https://goo.gl/UuykAe

17. Lobmaier PP, Kunøe N, Gossop M, Waal H. Naltrexone depot formulations for opioid and alcohol dependence: a systematic review. CNS neuroscience \& therapeutics. 2011; 17: 629-636. Ref.: https://goo.gl/tDeCvH

18. Richmond R, Zwar N. Review of bupropion for smoking cessation. Drug Alcohol Rev. 2003; 22: 203220. Ref.: https://goo.gl/jbPpNi

19. Caixàs A, Albert L, Capel I, Rigla M. Naltrexone sustained-release/bupropion sustained-release for the management of obesity: review of the data to date. Drug Des Devel Ther. 2014; 8: 1419-1427. Ref.: https://goo.gl/22qx1w

20. Finelli C, Tarantino G. Have guidelines addressing physical activity been established in nonalcoholic fatty liver disease? World journal of gastroenterology: WJG. 2012; 18: 6790-6800. Ref.: https://goo.gl/aBLACz

21. Freedman DS, Khan LK, Serdula MK, Ogden CL, Dietz WH. Racial and ethnic differences in secular trends for childhood BMl, weight, and height. Obesity (Silver Spring). 2006; 14: 301-308. Ref.: https://goo.gl/JmuT8f

22. Griffiths C, Gately P, Marchant PR, Cooke CB. Cross-sectional comparisons of BMI and waist circumference in British children: mixed public health messages. Obesity (Silver Spring). 2012; 20 : 1258-1260. Ref.: https://goo.gl/5eh9q8 